\title{
mTOR inhibition: a promise for a young heart
}

\section{Stefany B. A. Cau and Rita C. Tostes*}

Department of Pharmacology, Medical School of Ribeirao Preto, Ribeirao Preto, São Paulo, Brazil

*Correspondence: rtostes@usp.br

\section{A Commentary on}

Perspectives of targeting mTORC1-S6K1 in cardiovascular aging

by Ming, X.-F., Montani, J.-P., and Yang, Z. (2012). Front. Physiol. 3:5. doi: 10.3389/ fphys.2012.00005

The mammalian target of rapamycin (mTOR) is a serine/threonine kinase that senses nutritional and cellular energy status and regulates cell growth, proliferation, and survival. Rapamycin (sirolimus), a naturally occurring antifungal macrolide isolated from the bacterium Streptomyces hygroscopicus in a soil sample from Easter Island of the Pacific Ocean (or Rapa Nui in the native language; Vezina et al., 1975), inhibits mTOR interaction with other molecular components (Brown et al., 1994). Rapamycin was shown to extend life span in mice, even when administered late in life (Harrison et al., 2009), suggesting that inhibition of the mTOR pathway may prolong human life span.

In this review, Ming et al. (2012) address the role of mTOR complex 1 and its downstream effector S6K1 (mTORC1S6K1) signaling pathway in aging and ageassociated diseases. The authors discuss the important new concept that augmented mTORC1-S6K1 signaling is not only critical in aging-related processes, but also provides a link between aging and cardiovascular disturbances, such as vascular and cardiac remodeling seen, e.g., in diabetes, arterial hypertension, atherosclerosis, and heart failure.
It has been hypothesized that some dietary regimes, like caloric restriction and methionine restriction, extends lifespan by decreasing mTOR activity (Kaeberlein et al., 2005). Accordingly, a comparison between the beneficial effects of pharmacological intervention with rapamycin and life style modification (caloric restriction) is also provided by the authors. One should keep in mind that the effects produced by caloric restriction and inhibition mTOR signaling are not straightforward correlated. Unlike caloric restriction, rapamycin treatment does not reduce animal size (Harrison et al., 2009) and caloric restriction fails to extend life span when initiated late in life (Masoro, 2005).

Mammalian target of rapamycin-S6K1 signaling and its specific inhibition emerge as a promising "treatment for aging," mainly through the prevention or reversion of cardiovascular aging. However, only intense research will clarify whether potential adverse side effects of mTOR inhibitors, such as suppression of the immune system (Weir et al., 2010), impairment of glucose tolerance (Houde et al., 2010), can be overcome by the beneficial effects in the treatment of age-related diseases (especially if they are to be used as a prophylactic treatment). Future research targeting mTOR downstream proteins, which would exhibit more specific actions, will also clarify the relevance of mTOR inhibition for the prophylactic treatment of aging or age-related diseases.

\section{REFERENCES}

Brown, E. J., Albers, M.W., Shin, T. B., Ichikawa, K., Keith, C. T., Lane, W. S., and Schreiber, S. L. (1994). A mammalian protein targeted by G1-arresting rapamycinreceptor complex. Nature 369, 756-758.
Harrison, D. E., Strong, R., Sharp, Z. D., Nelson, J. F., Astle, C. M., Flurkey, K., Nadon, N. L., Wilkinson, J. E., Frenkel, K., Carter, C. S., Pahor, M., Javors, M. A., Fernandez, E., and Miller, R.A. (2009). Rapamycin fed late in life extends lifespan in genetically heterogeneous mice. Nature 460, 392-395.

Houde, V. P., Brule, S., Festuccia, W. T., Blanchard, P. G., Bellmann, K., Deshaies, Y., and Marette, A. (2010). Chronic rapamycin treatment causes glucose intolerance and hyperlipidemia by upregulating hepatic gluconeogenesis and impairing lipid deposition in adipose tissue. Diabetes 59, 1338-1348.

Kaeberlein, M., Powers, R. W. III, Steffen, K. K., Westman, E. A., Hu, D., Dang, N., Kerr, E. O., Kirkland, K. T. Fields, S., and Kennedy, B. K. (2005). Regulation of yeast replicative life span by TOR and Sch9 in response to nutrients. Science 310, 1193-1196.

Masoro, E. J. (2005). Overview of caloric restriction and ageing. Mech. Ageing Dev. 126, 913-922.

Ming, X.-F., Montani, J.-P., and Yang, Z. (2012). Perspectives of targeting mTORC1-S6K1 in cardiovascular aging. Front. Physiol. 3:5. doi: 10.3389/ fphys.2012.00005

Vezina, C., Kudelski, A., and Sehgal, S. N. (1975). Rapamycin (AY-22,989), a new antifungal antibiotic. I. Taxonomy of the producing streptomycete and isolation of the active principle. J. Antibiot. 28, 721-726.

Weir, M. R., Diekmann, F., Flechner, S. M., Lebranchu, Y., Mandelbrot, D. A., Oberbauer, R., and Kahan, B. D. (2010). mTOR inhibition: the learning curve in kidney transplantation. Transpl. Int. 23, 447-460.

Received: 11 January 2012; accepted: 06 February 2012; published online: 22 February 2012.

Citation: Cau SBA and Tostes RC (2012) mTOR inhibition: a promise for a young heart. Front. Physio. 3:31. doi: 10.3389/fphys.2012.00031

This article was submitted to Frontiers in Vascular Physiology, a specialty of Frontiers in Physiology.

Copyright (C) 2012 Cau and Tostes. This is an open-access article distributed under the terms of the Creative Commons Attribution Non Commercial License, which permits noncommercial use, distribution, and reproduction in other forums, provided the original authors and source are credited. 